\title{
Nesting estimation and analysis of threats for Critically Endangered leatherback Dermochelys coriacea and Endangered olive ridley Lepidochelys olivacea marine turtles nesting in Congo
}

\author{
Marie-Clélia Godgenger, Nathalie Bréheret, Ga ËLle Bal \\ Karine N'Damité, Alexandre Girard and Marc Girondot
}

\begin{abstract}
Six marine turtle species are reported from the coastal waters of the Republic of the Congo. Among them, nesting by the Critically Endangered leatherback Dermochelys coriacea and Endangered olive ridley Lepidochelys olivacea marine turtles occurs annually from September to April on Congolese beaches. We developed a methodology to model the nesting season of marine turtles and apply it to the time series of nest counts for six nesting beaches monitored over 2-4 years. There is a peak of nesting activity in early January for leatherback turtles and early December for olive ridley turtles. We show a decline of olive ridley nests during this period whereas leatherback nesting increased, and propose that differential threats for these two species explain such a contrasted pattern.
\end{abstract}

Keywords Bycatch, Dermochelys coriacea, leatherback, Lepidochelys olivacea, marine turtle, nesting, olive ridley, threats

This paper contains supplementary material that can be found online at http://journals.cambridge.org

\section{Introduction}

arine turtles are recognized internationally as of con1 servation concern and all species are experiencing serious threats to their survival. The main threat appears to be accidental capture in fishing gear (Lewison \& Crowder, 2007) but other threats include pollution and changes to important turtle habitats, especially coral reefs, seagrass beds, mangrove forests and nesting beaches. Overharvesting of turtles and eggs, and predation of eggs and hatchlings

Marie-Clélia Godgenger and Marc Girondot* (Corresponding author) Université Paris-Sud, Laboratoire Ecologie, Systématique et Evolution, UMR 8079, Orsay F-91405, France and CNRS, Orsay F-91405, France. E-mail marc.girondot@u-psud.fr

KARINe N'DAmité Université Paris-Sud, Orsay, France and Association RENATURA, Pointe-Noire, Congo.

Nathalie Bréheret, Gaëlle Bal and Alexandre Girard Association RENATURA, Albens, France and Pointe-Noire, Congo.

*Also at: Département de Systématique et Evolution, Muséum National d'Histoire Naturelle de Paris, Paris, France.

Received 18 September 2007. Revision requested 3 December 2007. Accepted 4 March 2008. by foxes Vulpus spp., feral pigs Sus domestica, dogs Canis familiaris and goannas Varanus spp. are also a problem (Musick \& Lutz, 1997). The olive ridley Lepidochelys olivacea and leatherback Dermochelys coriacea marine turtles are categorized as Endangered and Critically Endangered, respectively, on the IUCN Red List (IUCN, 2008). Although these categories may not reflect the true status of marine turtles (Mrosovsky, 2004), they indicate concern about long-term survival prospects.

Marine conservation along the African coast has received little attention compared to other areas (Shumway, 1999), particularly for marine turtles (Formia et al., 2003), despite a recent summary of available information for the Atlantic coast (Fretey, 2001). All six of the Atlantic species of marine turtle (green turtle Chelonia mydas, leatherback, hawksbill Eretmochelys imbricata, olive ridley, loggerhead Caretta caretta and Kemp's ridley Lepidochelys kempii) have been reported to nest along this coast but few quantitative data are available (Fretey, 2001). There are reports, however, of high local consumption of eggs and meat of marine turtles (Barnett et al., 2004), as well as a high level of bycatch in fishing gear (Carranza et al., 2006; Lewison \& Crowder, 2007).

The number of nests laid by a marine turtle population can be used as an index of population size (Gerrodette \& Taylor, 1999) and from such an index it is possible to describe a trend for the population (Troëng et al., 2004; Girondot et al., 2007). Recent approaches to the use of such time-series data in environmental applications use a semi-parametric approach in which a time effect is included in the mean (Coull et al., 2001; Samoli et al., 2001). The advantage of such an approach is that it models non-stationarity in the time effect more flexibly.

Partial nightly nest counts were made over 4 years along the coast of the Republic of the Congo. The data were analysed using a derivation of a statistical model of nesting season developed for nesting beaches in French Guiana, South America (Girondot et al., 2006). This model was originally developed to describe the phenology of a marine turtle nesting season for the purposes of filling in gaps from incomplete monitoring over the course of a nesting season. We show that there is a positive trend in the numbers of leatherback turtles nesting but a negative trend for olive 
ridley turtles. This difference is discussed with respect to differences in ocean habitat use by these two species and threats along the Congolese coast.

\section{Study area}

The Republic of the Congo has a coastline of $170 \mathrm{~km}$ on the Atlantic (Fig. 1), the majority of which comprises sandy beaches in front of mangroves. There are emerged rocks around Pointe Indienne and Pointe Noire (Fig. 1). The RENATURA association patrols the turtle nesting beaches of Cabinda frontier, Djeno, Mvassa, Bas-Kouilou Sud, Tchissaou and Bellelo (Fig. 1). The Wildlife Conservation Society monitors the northern beaches, within the Conkouati-Douli National Park, but no data are currently available.

\section{Methods}

Morning patrols for nest counts were made on two beaches (along a total of $20 \mathrm{~km}$ in 2003-2004 and 2004-2005) and six beaches (59 km in 2005-2006 and 2006-2007). In 20032006 daily morning nesting counts were performed. In 2006-2007 patrols were on a daily basis on Djeno, Bellelo

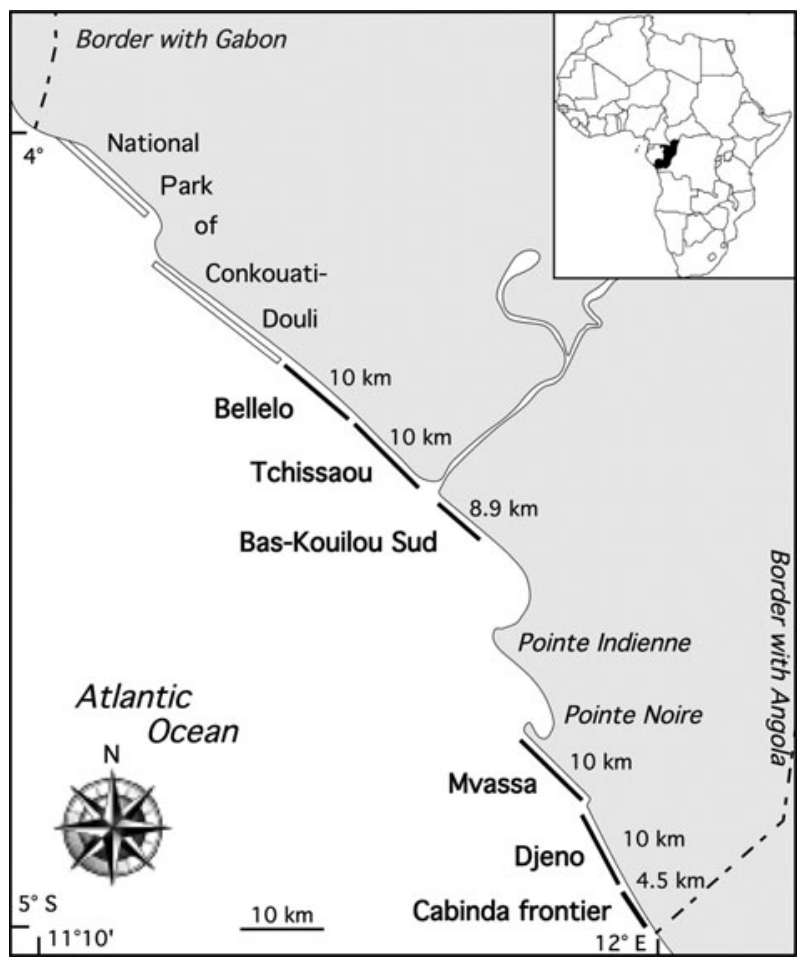

FIG. 1 The coast of Congo. Beaches are indicated with bold lines parallel to the coast. Filled lines indicate beaches monitored by RENATURA and open lines are the beaches located within the National Park of Conkouati-Douli monitored by the Wildlife Conservation Society (not included in this study). The total coastline measures $170 \mathrm{~km}$. International borders are shown in dashed lines. and Mvassa beaches, and weekly on the other three beaches, during the entire nesting season (November-April). Because adult females leave wide, deep tracks on the beach after nesting it is relatively easy to identify a sea turtle nesting crawl (Schroeder \& Murphy, 1999). Experienced field workers can differentiate tracks with a body pit, indicating a successful oviposition, from tracks of a female disturbed during the nesting process that has not deposited eggs.

\section{Nesting season model}

The model was a modification of that developed by Girondot et al. (2006) to describe a sea turtle nesting season. It is briefly described here and in more detail in the Appendix. Nesting seasons of marine turtles are generally $3-5$ months long and are typically characterized by a low number of nests at the start and end of the season, a peak of nesting in the middle of the season, and generally $<_{1}$ nest per month outside the nesting season. This typical pattern can be modelled using the product of two sigmoid equations, the first one ranging from $o$ to 1 and the second one from 1 to 0 . The inflexion point of the first sigmoidal curve occurs at day $P_{1}$ with slope $S_{1}$, and of the second sigmoidal curve at day $P_{2}$ with slope $S_{2}$. Parameters $K_{1}$ and $K_{2}$ allow the sigmoidal curves to be asymmetrical around the respective inflection points. The total number of nests laid during the season is derived from multiplication of the scaling parameter max, which is defined as the number of new nests laid on the peak nesting day of the entire season. In the use of this model for beaches in the Congo the daily number of nests outside the nesting season is fixed at $o$ as no nests have been observed during this time (GB and NB, pers. obs.). The nesting season boundaries used here are from 1 September to 30 April.

\section{Error distribution and parameter estimation}

Parameters for the model were fitted using maximum likelihood statistics. Parameter values that maximized the likelihood of observations in the model were determined using a non-linear fitting algorithm (Lasdon et al., 1978; Lasdon \& Waren, 1981). In a previous analysis, Girondot et al. (2006) postulated that an estimate of nest numbers for a particular day could be approximated by a Gaussian (normal) distribution, with variable standard deviation to take into account heteroskedasticity. However, the assumption that a Gaussian probability distribution underlies the observed data is problematic for several reasons. Firstly, the Gaussian distribution represents probabilities associated with a continuous variable that can theoretically take on any possible value within a plausible range, including fractional values if the observational method has the necessary precision. Nest numbers are discrete counts sub-sampled and can only be represented by non-negative integers. Such data are also characterized by low mean values and high variances. 
Because of its symmetry the normal probability distribution can imply a substantial probability of observing a negative number of nests. When a Gaussian approximation is used to estimate error distributions for the Congo nesting data we found that in cases when the number of nests was similar to the variance, the error distribution was biased. The least-square fitting method used by Gratiot et al. (2006) suffers the same bias because least-square fitting assumes homoskedastic Gaussian error distribution (Hilborn \& Mangel, 1997). Generally, both homoskedasticity and Gaussian distribution are not valid assumptions when analysing time series of marine turtle nest counts.

In contrast, the use of a Poisson distribution for nest counts appears to correct these problems. This is a discrete probability distribution that expresses the probability of a number of events occurring in a fixed period of time if these events occur with a known average rate and are independent of the time since the last event. The probability that there are exactly $x$ occurrences ( $x$ being a nonnegative integer, $x=0,1,2, \ldots)$ when the expected number of occurrences is $\lambda$ is represented by:

$$
f(x, \lambda)=\frac{e^{-\lambda} \lambda^{x}}{x !}
$$

Model selection and quality of fit

Model selection was performed using the Akaike Information Criterion (AIC; Akaike, 1974). This is a ranking measure that takes into account the quality of the fit of the model to the data while penalizing for the number of parameters used:

$$
\mathrm{AIC}=-2 \ln \mathrm{L}+2 \mathrm{M}
$$

where $L=$ maximum likelihood and $M=$ the number of parameters. The models with the lowest values of AIC were retained as candidate models and the $\Delta_{\text {AIC }}$ value was calculated as the difference in value of AIC between a particular model and the one with the lowest AIC. Akaike weights $\left(w_{i}=\exp \left(-\Delta_{\text {AIC }} / 2\right)\right.$, normalized to 1$)$ were used to evaluate the relative support for the various models tested (Burnham \& Anderson, 2002). Akaike weights can be directly interpreted as conditional probabilities for each model. Ideally, the model with the lowest AIC is retained for further testing. When two or more models possessed similar Akaike weights the model with the lowest number of parameters was selected.

The quality of fitting was estimated by comparison of the deviance of the saturated model $D_{\text {full }}$ (i.e. each observation is used to calculate the likelihood) with the deviance of the fitted model $D_{\text {fitted. }}$ The statistic $D_{\text {fitted }}-D_{\text {full }}$ is distributed in the same manner as the $\chi^{2}$ distribution with degrees of freedom equal to the number of observations minus the number of parameters fitted from these observations.

\section{Standard error of parameters and nest number}

The standard error associated with the mean number of nests was estimated from a bootstrap sampling of the counts of nests (Efron \& Tibshirani, 1993). This alleviates the technical difficulties in estimating the confidence interval (CI) of the mean of a Poisson distribution (Sahai \& Khurshid, 1993). The bootstrap strategy cannot be used for beaches with only one count per week. In such cases, parameters describing the shape of the nesting season obtained from bootstrapped samples were used and only the scaling parameter max was fitted with all the nest count data for that beach.

The total number of nests deposited during the entire season was the sum of the number of nests laid per night. When the nest number for a particular night was known, the observed value was used for the total estimate. The CI of total nest number was estimated using the bootstrapped samples.

\section{Trend analyses}

Data are available for 4 years from only two nesting beaches: Djeno and Bellelo. The trend of the number of nests on these beaches was obtained based on an exponential growth model. The total number of nests per year was fitted using maximum likelihood with a Gaussian error model and a fitted standard deviation. To assess the trend of the population we compared the models: one based on the exponential growth model and the second constrained with a stable population. Akaike weights were used to evaluate the relative support for both models.

\section{Results}

The leatherback turtle nesting season

A single model of nesting season shape was implemented but the max value was beach- and year-specific. The likelihood of the model with $K_{1}$ and $K_{2}$ fitted or $K_{1}$ and $K_{2}$ fixed to o were similar $(-\ln (L)=1,075.94$ vs $1,075.95)$. Therefore the $K_{1}$ and $K_{2}$ values were discarded. The fit of the model could not be rejected (residual deviance $=1,262.68$, $\mathrm{df}=1,725$, $\mathrm{P}=1.0$ ). In 2005-2006 data for the beginning of the season were not available and thus we could not derive the parameters $P_{1}, S_{1}$ and $K_{1}$ for that season, which meant we could not test the year-specific model for nesting season shape. The total number of nests estimated for each year and beach are shown in Table 1 and the best-fit models used to estimate total number of nests for Djeno and Bellelo beaches in Fig. 2.

The olive ridley turtle nesting season

Because monitoring began after the olive ridley nesting season began each year, we could not adequately fit a model 
TABLE 1 Number of leatherback and olive ridley turtle nests recorded and corrected (see text for details) for partial temporal sampling from the 2003-2004 to 2006-2007 nesting seasons on six beaches along the Congolese coast (Fig. 1), with beach length and number of nights patrolled. The entire nesting season is 242 nights long from September to April.

\begin{tabular}{|c|c|c|c|c|c|}
\hline Nesting season & Beach name & Beach length $(\mathrm{km})$ & Nights patrolled & Nests recorded & $\begin{array}{l}\text { Corrected mean } \\
\text { no. of nests }(95 \% \mathrm{CI})\end{array}$ \\
\hline \multicolumn{6}{|c|}{ Leatherback turtle } \\
\hline \multirow[t]{2}{*}{ 2003-2004 } & Bellelo & 10 & 170 & 18 & $19.22(18.54-19.86)$ \\
\hline & Djeno & 10 & 158 & 52 & $59.94(57.94-63.55)$ \\
\hline \multirow[t]{2}{*}{ 2004-2005 } & Bellelo & 10 & 171 & 22 & $22.74(22.23-23.22)$ \\
\hline & Djeno & 10 & 162 & 51 & $54.33(52.69-56.33)$ \\
\hline \multirow[t]{7}{*}{ 2005-2006 } & Bellelo & 10 & 136 & 69 & $74.06(72.14-76.42)$ \\
\hline & Tchissaou & 10 & 7 & 3 & $49.14(38.47-63.2)$ \\
\hline & Bas Kouilou Sud & 8.9 & 8 & 5 & $78.76(69.86-87.59)$ \\
\hline & Mvassa & 10 & 8 & 6 & $92.81(82.27-103.16)$ \\
\hline & Djeno & 10 & 114 & 72 & $79.03(75.50-82.78)$ \\
\hline & Cabinda frontier & 4.5 & 8 & 3 & $47.42(41.56-52.86)$ \\
\hline & Total & & & & $421(380-466)$ \\
\hline \multirow[t]{7}{*}{ 2006-2007 } & Bellelo & 10 & 175 & 113 & $115.05(114.01-116.31)$ \\
\hline & Tchissaou & 10 & 167 & 75 & $77.42(76.16-78.77)$ \\
\hline & Bas Kouilou Sud & 8.9 & 8 & 2 & $28.41(25.18-31.62)$ \\
\hline & Mvassa & 10 & 12 & 9 & $128.96(114.42-143.56)$ \\
\hline & Djeno & 10 & 175 & 88 & 89.74 (88.82-90.82) \\
\hline & Cabinda frontier & 4.5 & 11 & 4 & $57.84(51.32-64.36)$ \\
\hline & Total & & & & $497(470-525)$ \\
\hline \multicolumn{6}{|c|}{ Olive ridley turtle } \\
\hline \multirow[t]{2}{*}{ 2003-2004 } & Bellelo & 10 & 170 & 47 & $65.24(53.03-78.96)$ \\
\hline & Djeno & 10 & 158 & 50 & $90.5(66.49-115.94)$ \\
\hline \multirow[t]{2}{*}{ 2004-2005 } & Bellelo & 10 & 171 & 40 & $48.2(41.52-55.43)$ \\
\hline & Djeno & 10 & 162 & 59 & $79.62(63.10-95.49)$ \\
\hline \multirow[t]{7}{*}{ 2005-2006 } & Bellelo & 10 & 136 & 30 & $46.56(32.39-57.64)$ \\
\hline & Tchissaou & 10 & 7 & 2 & $47.61(31.86-63.09)$ \\
\hline & Bas Kouilou Sud & 8.9 & 8 & 1 & $22.9(14.73-30.81)$ \\
\hline & Mvassa & 10 & 8 & 4 & $85.54(54.64-115.5)$ \\
\hline & Djeno & 10 & 114 & 66 & $89.11(69.27-105.96)$ \\
\hline & Cabinda frontier & 4.5 & 8 & 9 & $187.36(135.04-237.43)$ \\
\hline & Total & & & & $479(337-610)$ \\
\hline \multirow[t]{7}{*}{ 2006-2007 } & Bellelo & 10 & 175 & 42 & $48.2(42.65-53.82)$ \\
\hline & Tchissaou & 10 & 167 & 49 & $70.63(54.6-84.68)$ \\
\hline & Bas Kouilou Sud & 8.9 & 8 & 2 & $31.09(23.13-38.86)$ \\
\hline & Mvassa & 10 & 12 & 10 & $167.48(121.5-211.48)$ \\
\hline & Djeno & 10 & 175 & 44 & $53.83(46.13-60.44)$ \\
\hline & Cabinda frontier & 4.5 & 11 & 4 & $68.37(49.44-86.47)$ \\
\hline & Total & & & & $439(337-535)$ \\
\hline
\end{tabular}

to describe the shape of the beginning of the nesting season. Alternatively, a constraint on $S_{1}$ can be established from the value of $S_{2}$. For example, if $S_{1}=S_{2}$, then the shape of the nesting season is symmetrical around the peak of the nesting season. We fitted several time series of olive ridley nest numbers from French Guiana, South America (not shown), which showed that the end of the nesting season was sharper than the beginning $\left(\left|S_{2}\right|>\left|S_{1}\right|\right)$. The average ratio $\left|S_{2}\right| /\left|S_{1}\right|$ was 1.33 . We used this ratio in the present analyses to constrain $S_{1}$ based on $S_{2}$. The $P_{1}$ value was still fitted.

The likelihood of the model with $K_{1}$ and $K_{2}$ fitted or $K_{1}$ and $K_{2}$ fixed to 0 were similar $(-\ln (L)=875.2$ vs 876.56$)$.
Therefore, the $K_{1}$ and $K_{2}$ values were set to 1 for the remainder of the analyses. The fit of the model could not be rejected (residual deviance $=1,106.50, \mathrm{df}=1,695, \mathrm{P}=1$ ). Again a yearly-based model could not be implemented because of a lack of early nesting season data. The total number of nests estimated for each year and beach is shown in Table 1 and the model fits for Djeno and Bellelo beaches are shown in Fig. 3.

\section{Trend analyses}

For leatherback turtles the instantaneous growth rate of the exponential growth model $(r)$ was positive for both beaches 

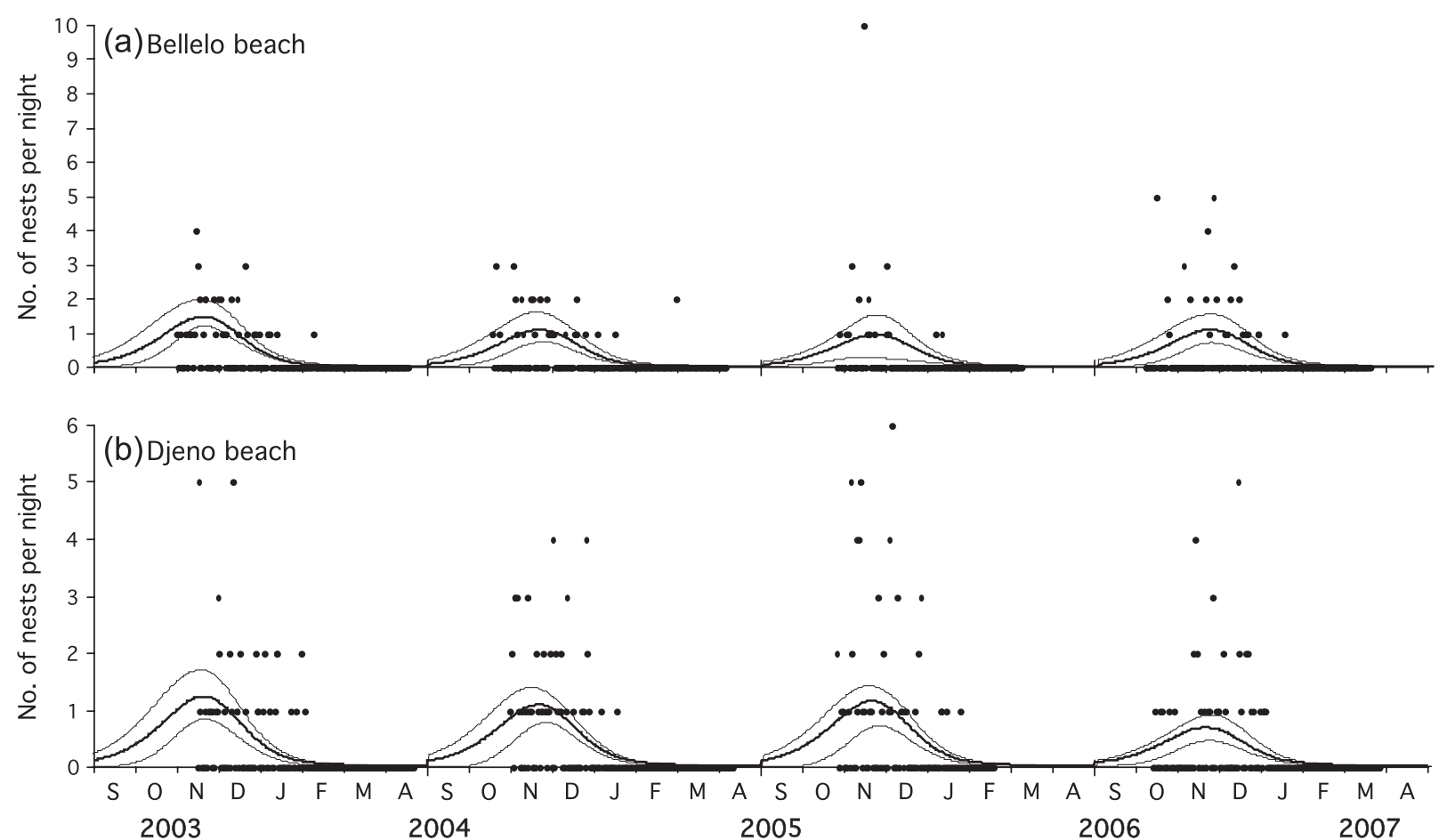

FIG. 2 Number of leatherback turtle nests on (a) Bellelo and (b) Djeno beaches (Fig. 1) monitored over four nesting seasons (SeptemberApril). The bold line is the best-fit distribution for daily nest number and the two surrounding lines are its $95 \%$ confidence intervals based on bootstrapped samples.

(o.62 and 0.16 for Bellelo and Djeno beach, respectively; Fig. 4a). When compared with a constrained constant model $(r=0)$, the model with $r$ fitted was selected (AIC 50.74 vs 66.60; Akaike weight $=0.999)$. For olive ridley turtles $r$ was negative for both beaches (-0.10 and -0.12 for Bellelo and Djeno beach, respectively; Fig. 4 b). When compared with a constrained constant model $(r=0)$ the model with $r$ fitted was selected (AIC 50.51 vs 53.78; Akaike weight $=0.830$ ). In conclusion, the trend for these four seasons on these two beaches was positive for leatherback turtles but negative for olive ridley turtles.

\section{Discussion}

In 1999, at the initiative of the Convention of Migratory Species of Wild Animals (CMS, also known as the Bonn Convention), an international conference was organized in Abidjan, Côte d'Ivoire, for the conservation of sea turtles

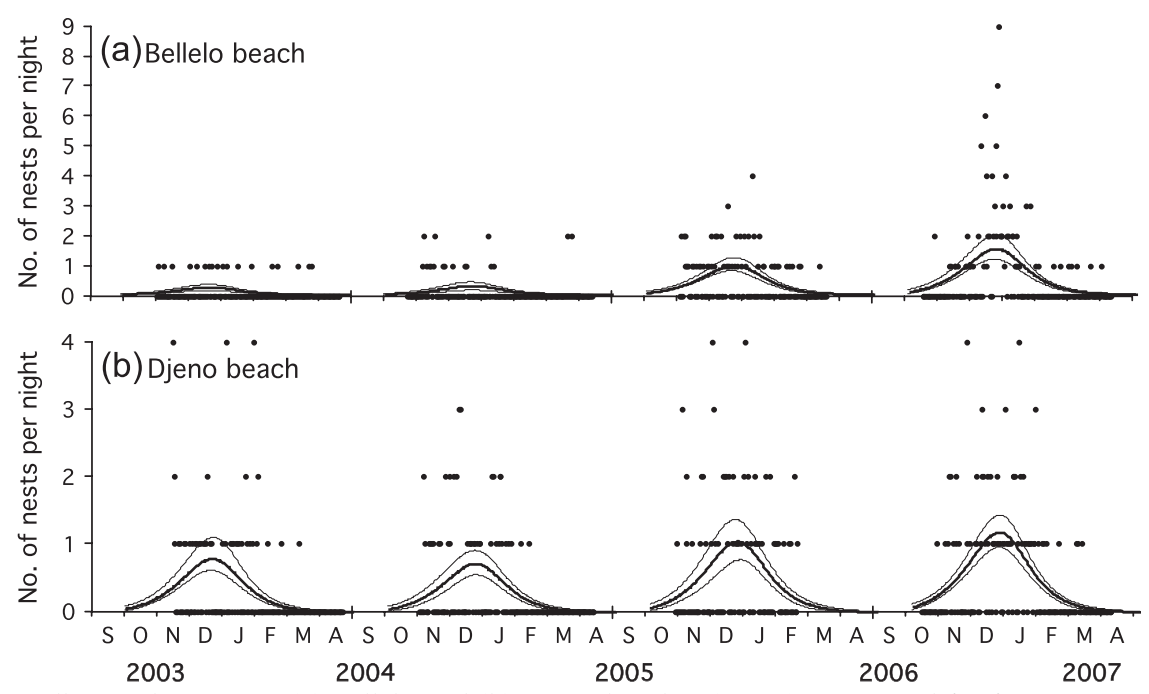

FIG. 3 Number of olive ridley turtle nests on (a) Bellelo and (b) Djeno beaches (Fig. 1) monitored for four nesting seasons (SeptemberApril). The bold line is the best-fit distribution for daily nest number and the two surrounding lines are its $95 \%$ confidence intervals based on bootstrapped samples. 

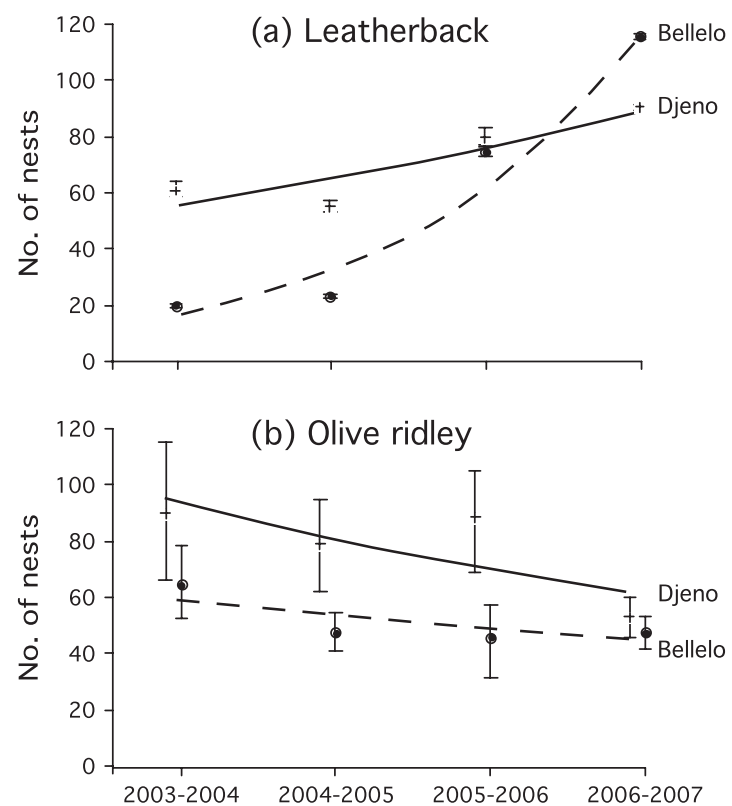

Fig. 4 Trends in the number of leatherback and olive ridley turtle nests on Bellelo and Djeno beaches (Fig. 1) over four nesting seasons.

in West Africa. The conference brought together 18 countries and the Abidjan Memorandum was adopted, the first paragraph of which notes that 'the populations of marine turtles frequenting the territorial waters and beaches of the Atlantic coast of Africa, from the Strait of Gilbraltar to the Cape of Good Hope, including Macaronesia, are seriously threatened'. However, at that time and until now, no quantitative data on these threats, or on the population status of marine turtles, have been available for these West African countries (Fretey, 2001; Formia et al., 2003). Knowledge of the status of marine turtles in the Congo is limited and only anecdotal information is available (Fretey, 2001). However, the little information available indicates that dead marine turtles are frequently observed on the beaches (Billes, 2000) and that marine turtles are sold in Congolese markets (Devaux, 1998). Information on threats to marine turtles in Congolese waters are of importance because migratory corridors between foraging and breeding zones are suspected to cross these waters (Fretey, 2001).

The methodology we used to analyse time series of nest counts for Congolese beaches appears to be well suited to cope with the various constraints of typical data collected on marine turtle nesting. It can be applied to both long and short time series and allows for hypotheses to be tested using environmental covariates that influence the phenology of nesting (Girondot et al., 2006). When applied to the Congo data, the fit of the model used in the present study appears suitable and no compensation for zero-inflation was necessary (Agarwal et al., 2002; Cunningham \& Lindenmayer, 2004).

The total number of nests was 479 (95\% CI, 337-610) in 2004-2005 and 439 (95\% CI, 337-535) in 2005-2006 for olive ridley turtles and 421 (95\% CI, 380-466) in 2004-2005 and 497 (95\% CI, 470-525) in 2005-2006 for leatherback turtles. Occasionally, green turtles also nest in this area but the rarity of the observations makes any analysis impossible. Female nesting populations cannot be estimated because of the lack of information on mean number of nests per turtle in the region.

Olive ridley nesting activity decreased over the 4 years of monitoring whereas leatherback nesting increased on the same two beaches during the same period. Many factors could cause variation in the observed level of nesting in one particular location: abandonment of nesting beach by nesting females, a change in number of years between successive nesting season, or change in the mean number of nests per female (Girondot et al., 2007). Sampling effects could also produce an apparent increase in nest density from year to year if the field workers receive improved training. For the data presented here, however, such a sampling bias does not appear to have occurred because the nesting density for one species increased whilst the other decreased.

Another possible cause for the trend we observed could be an artefact of the assumption that we used to define the shape of the beginning of the nesting season of olive ridley turtles $\left(\left|S_{2}\right| /\left|S_{1}\right|=1.33\right)$. However, we think this solution is preferable to using a symmetrical shape $\left(\left|S_{2}\right|=\left|S_{1}\right|\right)$ as implemented by Gratiot et al. (2006). Several different populations of marine turtles display asymmetrical peaked patterns associated with their nesting season (Diamond, 1976; Steyermark et al., 1996; Duque \& Paez, 2000). For olive ridley turtles the estimates of total number of nests for one particular year or beach should be viewed with caution but the relative changes during these four seasons were not altered by our assumption. Based on our results we recommend that monitoring of the beach should begin in early September to capture the beginning of the nesting season.

The differential trends in the nesting patterns of olive ridley and leatherback turtles may be linked to the at-sea threats to these species. Despite a lack of quantitative data

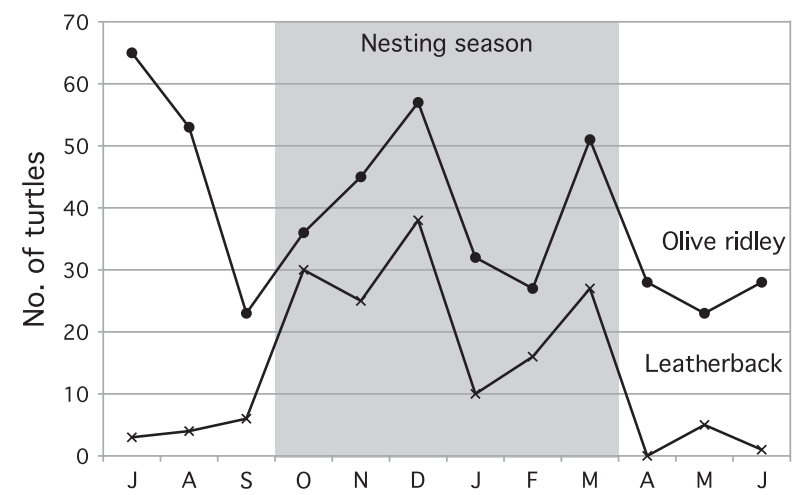

FIG. 5 Number of live turtles released from fishing nets in Congolese coastal waters during the year 2006. Note that the beginning of the year is shifted to present the nesting season in the centre of the graph. 


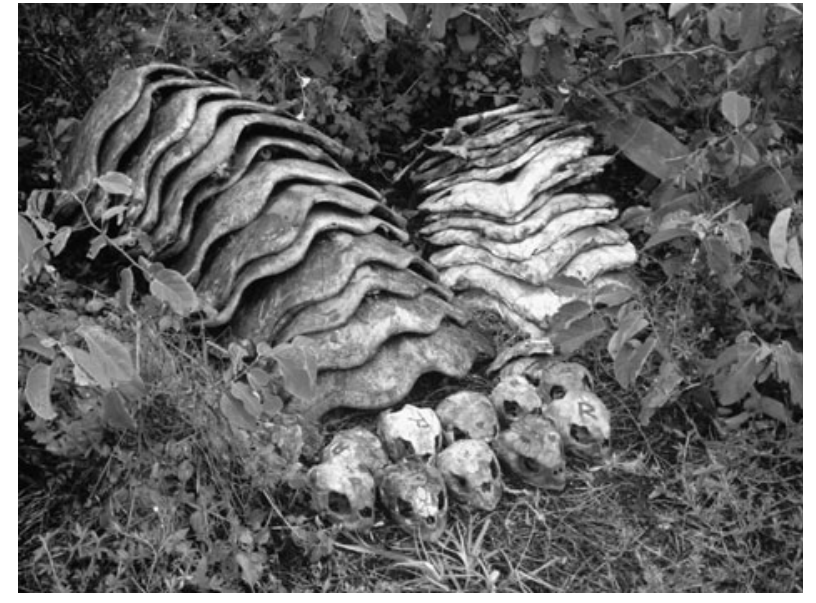

Plate 1 Olive ridley carcasses behind Tchissaou beach (Fig. 1).

on incidental captures in fisheries in this region, such interactions appear to be frequent. During 2005-2006 communication was established between RENATURA and local fishermen such that when a turtle was caught a local member of the RENATURA association was contacted. If the turtle was freed alive, material was given to repair the fisherman's net. A total of 1,500 releases occurred in this time, permitting an improved insight into the seasonal use of coastal habitat by marine turtles. Olive ridley turtles are present year-round in coastal waters, whereas leatherback turtles are typically present only during the nesting season (Fig. 5). In addition, the much smaller size and mass of olive ridley compared to leatherback turtles could result in different threats to these two species with respect to retention after incidental capture in fisheries. Piles of olive ridley carapaces are sometimes observed near the beaches (Plate 1). Thus, the apparent differing nesting trends of these two species could be a direct consequence of relatively higher mortality of olive ridley turtles in the local fisheries.

The 4-year time-series are too short to draw definitive conclusions about the population status of leatherback and olive ridley turtles nesting on Congolese beaches. Nonetheless, we urge local managers in Congo to support the efforts of RENATURA and fishermen to release accidentally trapped marine turtles. Unfortunately, this release programme stopped in 2007 due to lack of funds, probably leading to the incidental capture and death of thousands of marine turtles before the programme was reinitiated in 2008 .

\section{Acknowledgements}

We thank the following organizations for their support of the RENATURA association: Ecofac (Forest Ecosystem of Central Africa) of the EU via network Protomac (Protection of Marine Turtles of Central Africa) and Rapac (Network of Protected Areas of Central Africa). The Fonds français pour l'environnement mondial (French Agency for Development), the Marine Conservation Society (Turtles Conservation Fund/MCS), the Nature et Découvertes fund and Gecko (Total E\&P) also supported the field work. We also thank Societies Puma, MAG Industrie, Librairie Paillet, Optique Congo, Socotrans, Codisco and the Association des pêcheurs et chasseurs sportifs du Congo for their support. The work of RENATURA is supported by the Ministere des Eaux et Forêts de la République du Congo. Numerous field workers helped to collect the data used in this analysis; we thank them for their constant effort. This article benefited from corrections by Bryan Wallace, Drangea Lyndhurst, Josephine Humphreys, Matthew Godfrey and two anonymous referees.

\section{References}

Agarwal, D.K., Gelfand, A.E. \& Citron-Pousty, S. (2002) Zero-inflated models with application to spatial count data. Environmental and Ecological Statistics, 9, 341-355.

Akaike, H. (1974) A new look at the statistical model identification. IEEE Transactions on Automatic Control, 19, 716-723.

Bal, G., Breheret, N. \& Vanleeuwe, H. (2007) An update on sea turtle conservation activities in the Republic of Congo. Marine Turtle Newsletter, 116, 9-10.

Barnett, L.K., Emms, C., Jallow, A., Cham, A.M. \& Mortimer, J.A. (2004) The distribution and conservation status of marine turtles in The Gambia, West Africa: a first assessment. Oryx, 38, 203-208.

Billes, A. (2000) Mayumba, site d'importance internationale pour la ponte des tortues marines. Canopee, 16, 1-2.

Burnham, K.P. \& Anderson, D.R. (2002) Model Selection and Multimodel Inference: A Practical Information-Theoretic Approach. Springer-Verlag, New York, USA.

Carranza, A., Domingo, A. \& Estrades, A. (2006) Pelagic longlines: a threat to sea turtles in the Equatorial Eastern Atlantic. Biological Conservation, 131, 52-57.

Coull, B.A., Schwartz, J. \& Wand, M.P. (2001) Respiratory health and air pollution: additive mixed model analyses. Biostatistics, 2, 337-349.

Cunningham, R.B. \& Lindenmayer, D.B. (2004) Modeling count data of rare species: some statistical issues. Ecology, 86, 1135-1142.

DEVAUX, B. (1998) La tortue martyre. Livre blanc sur le martyrologue des tortues et leur exploitation par l'homme. Edition SOPTOM, Gonfaron, France.

DiAmond, A.W. (1976) Breeding biology and conservation of hawksbill turtles, Eretmochelys imbricata L., on Cousin Island, Seychelles. Biological Conservation, 9, 199-215.

Duque, V.M. \& PAEz, V.P. (2000) Nesting ecology and conservation of the leatherback turtle, Dermochelys coriacea, at La Playona, Chocoan Gulf of Uraba (Colombia), in 1998. Actualidades Biologicas Medellin, 22, 37-53.

Efron, B. \& Tibshirani, R.J. (1993) An Introduction to the Bootstrap. Monographs on Statistics and Applied Probability, No. 57. Chapman and Hall, London, UK.

Formia, A., Timari, M., Fretey, J. \& Billes, A. (2003) Sea turtle conservation along the Atlantic coast of Africa. Marine Turtle Newsletter, 100, 33-37.

Fretey, J. (2001) Biogeography and Conservation of Marine Turtles of the Atlantic Coast of Africa. UNEP/CMS Secretariat 6, Bonn, Germany. 
Gerrodette, T. \& Taylor, B.L. (1999) Estimating population size. In Research and Management Techniques for the Conservation of Sea Turtles (eds K.L. Eckert, K.A. Bjorndal, F.A. Abreu-Grobois \& M. Donnelly), pp. 67-71. IUCN/SSC Marine Turtle Specialist Group Publication No. 4. IUCN/SSC, Gland, Switzerland.

Girondot, M., Godfrey, M.H., Ponge, L. \& Rivalan, P. (2007) Historical records and trends of leatherbacks in French Guiana and Suriname. Chelonian Conservation and Biology, 6, 37-46.

Girondot, M., Rivalan, P., Wongsopawiro, R., Briane, J.-P., Hulin, V., Caut, S. et al. (2006) Phenology of marine turtle nesting revealed by a statistical model of the nesting season. BMC Ecology, 6, 11.

Gratiot, N., Gratiot, J., De Thoisy, B. \& Kelle, L. (2006) Estimation of marine turtles nesting season from incomplete data; statistical adjustment of a sinusoidal function. Animal Conservation, 9, 95-102.

Hilborn, R. \& Mangel, M. (1997) The Ecological Detective. Confronting Models with Data. Princeton University Press, Princeton, USA.

IUCN (2008) 2008 IUCN Red List of Threatened Species. IUCN, Gland, Switzerland. Http://www.redlist.org [accessed 24 October 2008].

Lasdon, L.S. \& Waren, A.D. (1981) GRG2-An all FORTRAN general purpose nonlinear optimizer. ACM Sigplan Bulletin, $30,10-11$.

Lasdon, L.S., Waren, A.D., Jain, A. \& Ratner, M. (1978) Design and testing of a Generalized Reduced Gradient code for nonlinear programming. ACM Transactions on Mathematical Software, $4,34-50$.

Lewison, R.L. \& Crowder, L.B. (2007) Putting longline bycatch of sea turtles into perspective. Conservation Biology, 21, 79-86.

Mrosovsky, N. (2004) Predicting Extinction: Fundamental Flaws in IUCN's Red List System, Exemplified by the Case of Sea Turtles. Department of Zoology, University of Toronto, Toronto, Canada.

Musick, J.A. \& LuTz, P.L. (eds) (1997) The Biology of Sea Turtles. CRC Press, Boca Raton, USA.

OMORI, Y. (2003) Estimation for unequally spaced time series of counts with serially correlated random effects. Statistics and Probability Letters, 63, 1-12.

SAHAi, H. \& Khurshid, A. (1993) Confidence intervals for the mean of a Poisson distribution: a review. Biometrical Journal, 35, 857-867.

Samoli, E., Schwartz, J., Wojtyniak, B., Touloumi, G., Spix, C., BALDUCCI, F. et al. (2001) Investigating regional differences in short-term effects of air pollution on daily mortality in the APHEA project: a sensitivity analysis for controlling long-term trends and seasonality. Environmental Health Perspectives, 109, 349-353.

Schroeder, B. \& Murphy, S. (1999) Population surveys (ground and aerial) on nesting beaches. In Research and Management Techniques for the Conservation of Sea Turtles (eds K.L. Eckert, K.A. Bjorndal, F.A. Abreu-Grobois \& M. Donnelly), pp. 45-55. IUCN/SSC Marine Turtle Specialist Group Publication No. 4. IUCN/SSC, Gland, Switzerland.

Shumway, C.A. (1999) Forgotten Waters: Freshwater and Marine Ecosystems in Africa. Strategies for Biodiversity Conservation and Sustainable Development, Boston University, Boston, USA.

Steyermark, A.C., Williams, K., Spotila, J.R., Paladino, F.V., Rostal, D.C., Morreale, S.J. et al. (1996) Nesting leatherback turtles at Las Baulas National Park, Costa Rica. Chelonian Conservation and Biology, 2, 173-183.

Troëng, S., Chacón, D. \& Dick, B. (2004) Possible decline in leatherback turtle Dermochelys coriacea nesting along the coast of Caribbean Central America. Oryx, 38, 395-403.

Verhulst, P.F. (1846) Deuxième mémoire sur la loi d'accroissement de la population. Mémoires de l'Académie Royale des Sciences, des Lettres et des Beaux-Arts de Belgique, 20, 1-32.

\section{Appendix}

The appendix for this article is available online at http:// journals.cambridge.org

\section{Biographical sketches}

Marie-Clélia Godgenger studied theoretical population dynamics applied to marine turtles for her MSc. NATHALIE BRÉHERET and GAËLLE BAL are founder members of RENATURA and have lived and worked in Congo, where they manage the Association's field work, since 2000. KARINE N'DAMITÉ studied ecotoxicology for her MSc, with both RENATURA in Congo and the Laboratoire Ecologie, Systématique et Evolution in Paris, France. Alexandre Girard is a veterinary surgeon and founder member of RENATURA. He manages the activities of the Association in France. MARC GIRONDOT has worked for the conservation of marine turtles since 1985, using both molecular tools and modelling of population dynamics. His other research interests are the evolution of mineralized tissues and the evolution of temperature-dependent sex determination in reptiles. 